\title{
Radical Cyclizations of Bromo Acylsilanes and Intramolecular Trapping of the Rearranged $\alpha$-Silyloxy Radicals
}

\author{
Yeun-Min Tsai,* Kuo-Hsiang Tang and Weir-Torn Jiaang \\ Department of Chemistry, National Taiwan University, Taipei, Taiwan 106, Republic of China
}

Key Words: acylsilane; tandem radical cyclization; 1,5-hydrogen atom transfer, radical Brook rearrangement

\begin{abstract}
Radical 1,5-exo cyclizations of acylsihnes involving secondary radicals are quite effective. In contrast, 1,6-exo cyclizations are more sensitive toward steric effect. Tandem radical cyclization process can be designed.
\end{abstract}

Recently we reported a novel reaction involving addition of primary radicals to the carbonyl of acylsilanes ${ }^{1,2}$ (Scheme ). The resulting oxygen radical undergoes a possibly irreversible radical Brook rearrangement ${ }^{3}$ followed by hydrogen abstraction to give cyclopentyl silyl ether. In order to extend the synthetic applications, it is necessary to confirm that the cyclizations also proceed for secondary radicals as one may suspect that further substitution at the radical center will retard the cyclization due to steric effect. Now we wish to report the successful addition of secondary radicals to acylsilanes and intramolecular trapping of the rearranged radicals.

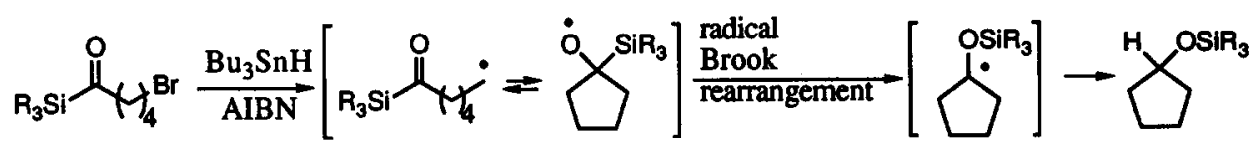

As shown in Table I, radical cyclization of the bromo acylsilane $1^{4}$ using the usual tin method gave successfully the product $2^{5}$ in good yield. In particular, this reaction could be performed very practically under rather concentrated condition in a very short period (entry 2). The reduction product 3 was isolated in small amount (5\%) only when 1 was directly mixed with tributyltin hydride and azobisisobutyronitrile (AIBN) in benzene and heated under reflux (entry 3). In contrast, the homologous bromo acylsilane $4^{4}$ under the same condition that worked well for 1 gave only the straight reduction product 5 (entry 4). However, the desired product $6^{6}$ could still be obtained in reasonable yield under more dilute concentration and lengthened time for the addition of the stannane (entry 6). Apparently intramolecular radical cyclizations of acylsilanes with secondary radicals are very efficient for five-membered ring formation but more difficult for six-membered ring formation.

Previously we reported that 1,5-exo cyclizations of acylsilanes involving primary radicals were very efficient and quite insensitive towards the variation of the silyl group. ${ }^{1}$ We assumed that this was also the case 
Table I. Cyclizations of acylsilanes with methyl substituted secondary bromides ${ }^{\mathrm{a}}$

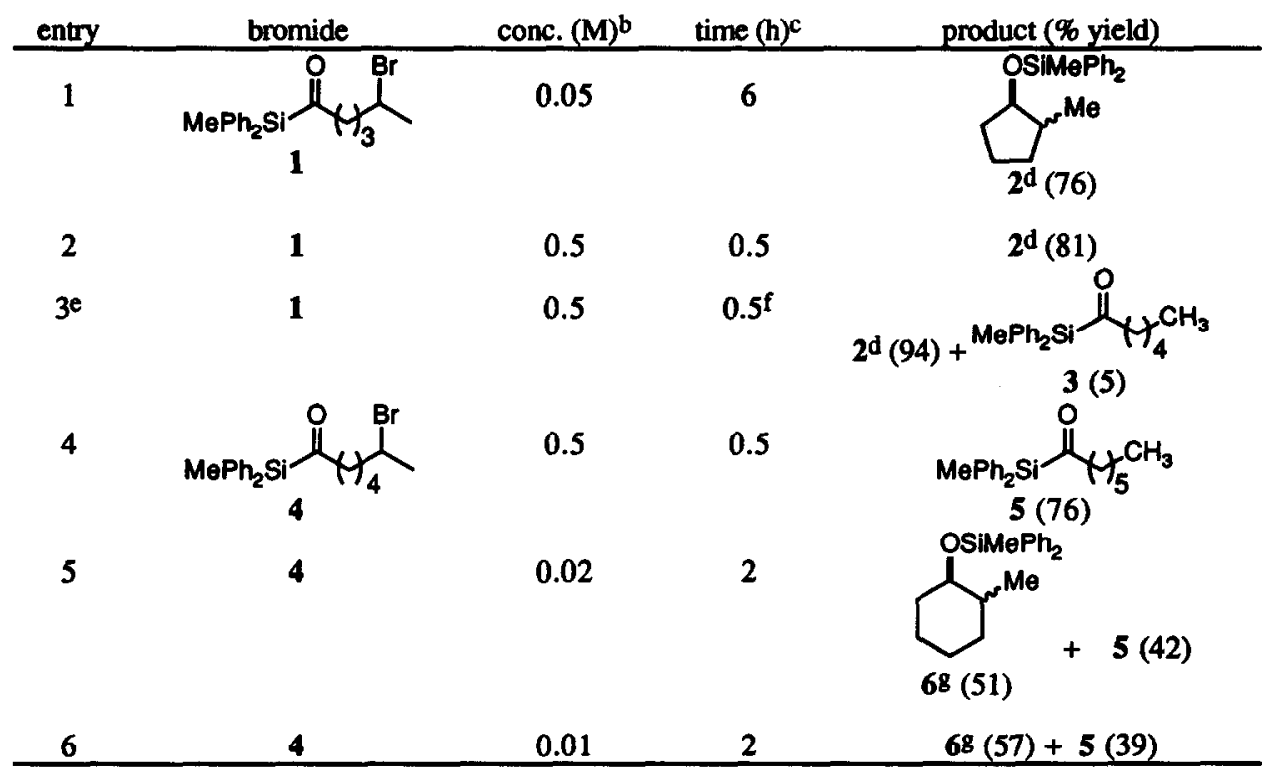

aplease see reference 1 for general procedure. bFinal concentration relative to the bromide.

${ }^{c}$ Addition time of the tributyltin hydride solution. ${ }^{d}$ A cis/trans (55/45) mixture (ref. 5). ePerformed by direct mixing of the reagents in benzene and heated at $80^{\circ} \mathrm{C}$. fReaction time. BA cis/trans (30/70) mixture (ref. 6).

for the corresponding 1,6-exo cyclizations based on the result with acyltrimethylsilane. However, the new findings with secondary radicals prompted us to investigate more about 1,6-exo cyclizations of acylsilanes with primary radicals. As shown in Table II, the 1,6-exo cyclization of $7^{4}$ was quite sensitive toward the change of the silyl group. More straight reduction product was observed (entry 2) when the silyl group was changed

Table II. Silyl group effect on 1,6-exo cyclization of acylsilanes involving primary radicalsa

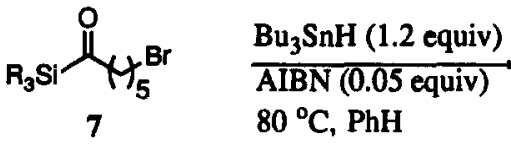

a $\mathrm{R}_{3} \mathrm{Si}=\mathrm{Me}_{3} \mathrm{Si} \quad$ b $\mathrm{R}_{3} \mathrm{Si}=t-\mathrm{BuMe}_{2} \mathrm{Si}$

c $\mathrm{R}_{3} \mathrm{Si}=\mathrm{MePh}_{2} \mathrm{Si}$ d $\mathrm{R}_{3} \mathrm{Si}=\mathrm{Me}_{2} \mathrm{PhSi}$

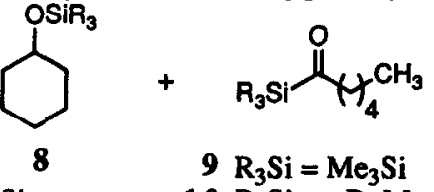

$10 \mathrm{R}_{3} \mathrm{Si}=t-\mathrm{BuMe}_{2} \mathrm{Si}$

$11 \mathrm{R}_{3} \mathrm{Si}=\mathrm{Me}_{2} \mathrm{PhSi}$

\begin{tabular}{|c|c|c|c|c|}
\hline entry & bromide & conc. $(\mathbf{M})^{\mathbf{b}}$ & time (h)c & product (\% isolation yield); GC ratiod,e \\
\hline 1f & $7 \mathbf{a}$ & 0.05 & 6 & $8 a / 9 ; 5.7 / 1$ \\
\hline 2 & $7 \mathrm{~b}$ & 0.025 & 2 & $8 b(51) / 10(38) ; 1.8 / 1$ \\
\hline 3 & 7c & 0.05 & 6 & $8 c(81) / 3 ; 30 / 1$ \\
\hline 4 & 7d & 0.05 & 6 & 8d (79) /11; $11 / 1$ \\
\hline
\end{tabular}

aSee footnote $\mathrm{a}$ in Table I. bSee footnote $\mathrm{b}$ in Table I. cSee footnote $\mathrm{c}$ in Table I. dDetermined on the crude product. The reduction products were prepared independently for GC comparisons. fRef. 1. 


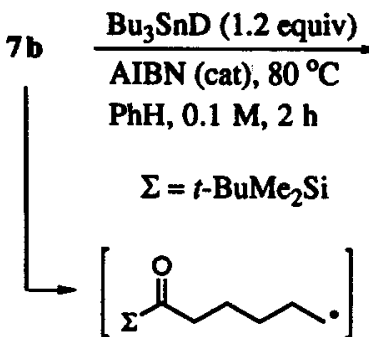

15

Scheme II

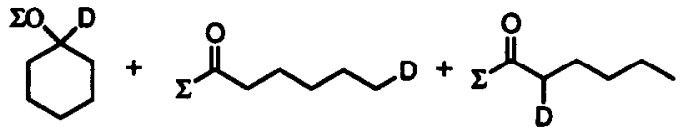

12

(60\%)
13
14

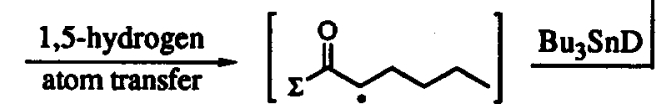

16

from trimethylsilyl (TMS) to $t$-butyldimethylsilyl (TBDMS) group. This is probably due to the steric effect exerted by TBDMS group. However, we were very surprised to find that 7c, with a seemingly very bulky methyldiphenylsilyl substituent, gave the highest proportion of $8 \mathrm{c}$. Similarly dimethylphenylsilyl substituted 7d also gave more cyclized product than 7a. We speculate that this enhancement of cyclization efficiency may be due to some unknown effects of the phenyl group.

In addition, when $7 \mathrm{~b}$ was treated with tributyltin deuteride (Scheme II), the cyclization product 12 (60\%) was isolated together with $36 \%$ of two uncyclized products 13 and $14\left(13 / 14=1 / 4.3\right.$ by ${ }^{1} \mathrm{H}$ NMR integration). ${ }^{7}$ The formation of 14 indicated that the initially formed radical 15 underwent a 1,5-hydrogen atom transfer ${ }^{8}$ to give 16. Subsequent deuterium atom abstraction of 16 gave 14. This experiment revealed a potential problem in 1,6-exo cyclization of acylsilanes. However, this problem appeared to be minor in the case of $7 c$ and $7 d$.

Having success with secondary radicals, we then turned our attention to the idea of tandem radical cyclizations involving trapping of the rearranged $\alpha$-silyloxy radical. We first synthesized the bromide 17 according to Scheme III. As shown in equation (1), we were gratified to find that treatment of 17 (a $0.05 \mathrm{M}$ final concentration in benzene) with tributyltin hydride (slow addition over $1 \mathrm{~h}$ ) at $80^{\circ} \mathrm{C}$ gave 18 exclusively. The corresponding alcohol 19 was isolated in $81 \%$ as a single stereoisomer after desilylation. The bicyclic alcohol 19 is an endo isomer confirmed by comparison with the literature data. $9 c$ This interesting endo selectivity is consistent with the results in similar systems. 9,10

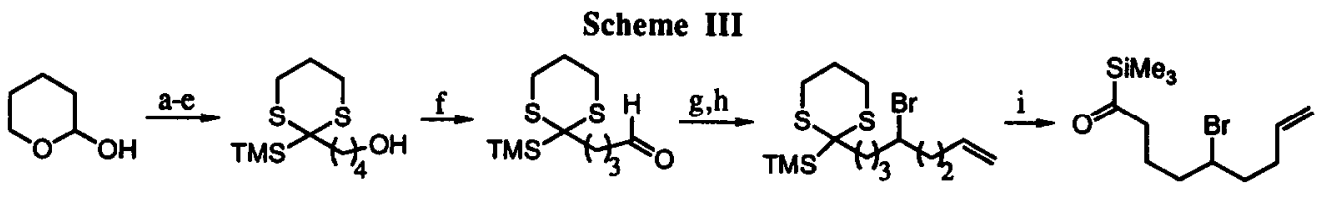

(a) 1,3-Propandithiol, $\mathrm{BF}_{3} \cdot \mathrm{OEt}_{2}, 100{ }^{\circ} \mathrm{C}$ (b) Dihydropyran, TsOH (cat); 88\% (c) $n$-BuLi/THF (d) TMSCl (e) $\mathrm{MeOH}$, TsOH (cat); $92 \%$ (f) $\mathrm{PCC} / \mathrm{CH}_{2} \mathrm{Cl}_{2} ; 64 \%$ (g) $\mathrm{CH}_{2}=\mathrm{CHCH}_{2} \mathrm{CH}_{2} \mathrm{MgBr} /$ ether, $97 \%$ (h) $\mathrm{CBr}_{4}, \mathrm{PPh}_{3}$ (i) $\mathrm{Tl}\left(\mathrm{ONO}_{2}\right)_{3}, \mathrm{MeOH}$, Celite, $-15^{\circ} \mathrm{C}, 5 \mathrm{~min} ; 66 \%$

$\mathrm{Bu}_{3} \mathrm{SnH}$
$\frac{(1.2 \text { equiv) }}{\mathrm{AIBN} \text { (cat) }}$
$\mathrm{PhH}, 80^{\circ} \mathrm{C}$

$1 \mathrm{~h}$

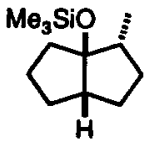

18

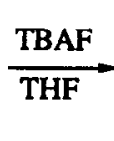<smiles>C[C@@H]1CCC2CCCC21O</smiles>

19 (81\%) 
In summary, radical cyclizations of acylsilanes involving secondary radicals are quite effective for 1,5-exo cyclization. In contrast, 1,6-exo cyclizations are more sensitive toward steric effect. A 1,5-hydrogen transfer reaction also competes with 1,6-exo cyclization. We also demonstrated in this letter the feasibility of trapping the rearranged $\alpha$-silyloxy radical intramolecularly to give bicyclo[3.3.0]octane skeleton which may be useful in the area of triquinane synthesis. ${ }^{11}$

Acknowledgment. Financial support by the National Science Council of the Republic of China is gratefully acknowledged (Grant 81-0208-M002-01).

\section{References and Notes}

1. Tsai, Y.-M.; Cherng, C.-D. Tetrahedron Lett. 1991, 32, 3515 and references cited therein.

2. For related works about acylgermanes, please see: (a) Curran, D. P.; Liu, H. J. Org. Chem. 1991, 56, 3463. (b) Curran, D. P.; Palovich, M. Synlett. 1992, 631.

3. Dalton, J. C.; Bourque, R. A. J. Am. Chem. Soc. 1981, 103, 699.

4. This bromide was prepared from the corresponding 2-silyl-1,3-dithiane and dibromide similar as the preparation of similar compounds described earlier (ref. 1).

5. The stereochemistry of 2 was determined by comparison with authentic trans-2 prepared from commercially available trans-2-methylcyclopentanol.

6. The stereochemistry of 6 was determined by comparison of the ${ }^{1} \mathrm{H} \mathrm{NMR}$ absorption (in $\mathrm{CDCl}_{3}$ ) at $\mathrm{C}(1)$ with that of cis- and trans-2-methylcyclohexanol reported in: Iguchi, S.; Nakai, H.; Hayashi, M.; Yamamoto, H.; Maruoka, K. Bull. Chem. Soc. Jpn. 1981, 54, 3033. The absorptions of cis- and trans-6 appeared at $\delta 3.75-3.90(\mathrm{~m})$ and $\delta 3.24(\mathrm{td}, J=10,4 \mathrm{~Hz}$ ), respectively.

7. This ratio was determined on a $500 \mathrm{MHz}$ NMR machine. The chemical shift (in $\mathrm{CDCl}_{3}$ ) of the protons at the $\alpha$-position of the carbonyl appeared at $\delta 2.55(\mathrm{t}, J=7 \mathrm{~Hz})$ for 13 , and $\delta 2.52(\mathrm{tt}, J=7.5,2.5$ $\mathrm{Hz}$ ) for 14. We thank Dr. Fen-Tair Luo of the Institute of Chemistry, Academia Sinica, Taipei, for kindly providing the spectra for us.

8. For a list of latest works about 1,5-hydrogen atom transfer reactions, see: Curran, D. P.; Somayajula, K. V.; Yu, H. Tetrahedron Lett. 1992, 33, 2295 and references cited therein. See also: Beckwith, A. L. J.; Raner, K. D. J. Org. Chem. 1992, 57, 4954.

9. (a) Shono, T.; Nishiguchi, I.; Ohmizu, H.; Mitani, M. J. Am. Chem. Soc. 1978, 100, 545. (b) Belotti, D.; Cossy, J.; Pete, J. P.; Portella, C. Tetrahedron Lett. 1985, 26, 4591. (c) Belotti, D.; Cossy, J.; Pete, J. P.; Portella, C. J. Org. Chem. 1986, 51, 4196. (d) Little, R. D.; Fox, D. P.; Hijfte, L. V.; Dannecker, R.; Sowell, G.; Wolin, R. L.; Moëns, L.; Baizer, M. M. J. Org. Chem. 1988, 53, 2287. (e) Yadav, V. K.; Fallis, A. G. Tetrahedron Lett. 1988, 29, 897. (f) Kariv-Miller, E.; Maeda, H.; Lombardo, F. J. Org. Chem. 1989, 54, 4022. (g) Molandar, G. A.; McKie, J. A. J. Org. Chem. 1992, 57, 3132.

10. For discussions about this endo selectivity, see: RajanBabu, T. V. Acc. Chem. Res. 1991, 24, 139 and references cited therein.

11. Hudlicky, T.; Rulin, F.; Lovelace, T. C.; Reed, J. W. in Studies in Natural Products Chemistry; Attaur-Rahman, Ed.; Elsvier: New York, 1989; Vol. 3, p 3. 